06.5;09.1

\title{
Анализ примесного состава синтетических НРНТ-алмазов методом лазерно-искровой эмиссионной спектроскопии в условиях лазерно-индуцированной модификации поверхности
}

\author{
(С) В.Ф. Лебедев ${ }^{1,2}$, Д.В. Булыга ${ }^{1}$, А.В. Колядин ${ }^{3}$ \\ ${ }^{1}$ Санкт-Петербургский национальный исследовательский университет информационных технологий, механики и оптики \\ (Университет ИТМО), Санкт-Петербург, Россия \\ ${ }^{2}$ Санкт-Петербургский государственный университет аэрокосмического приборостроения, Санкт-Петербург, Россия \\ 3 ООО „Нью Даймонд Технолоджи“, Санкт-Петербург, Россия \\ E-mail: lebedev@oi.ifmo.ru
}

Поступило в Редакцию 23 декабря 2019г.

В окончательной редакции 6 февраля 2020г.

Принято к публикации 6 февраля 2020 г.

\begin{abstract}
Проведено исследование примесного состава многосекторных пластин азот- и борсодержащих синтетических НРНТ-алмазов методом лазерно-искровой эмиссионной спектроскопии. Показано, что сравнительный анализ интенсивностей характерных атомарных и молекулярных полос в спектре излучения плазмы в процессе лазерно-индуцированной модификации поверхности образцов позволяет различать как тип алмаза, так и кристаллографическую ориентацию анализируемого сектора образца.
\end{abstract}

Ключевые слова: лазерно-искровая эмиссионная спектроскопия, лазерная абляция, алмазы, НРНТ-алмазы, графитизация.

DOI: 10.21883/PJTF.2020.09.49363.18164

Метод НРНТ (high pressure high temperature) позволяет выращивать крупные высококачественные монокристаллические алмазы, в том числе легированные, например, бором или азотом, как для ювелирной промышленности, так и для научных и технологических приложений [1-3]. Для крупных алмазов, выращиваемых методом НРНТ, характерна секторная структура, определяемая условиями роста кристалла. Наличие секторов с теми или иными кристаллографическими ориентациями определяется формой затравки, а также видом катализатора $[1,3]$. В структуре синтетических алмазов содержатся различного рода примеси и примесные центры, влияющие на их физические и оптические свойства $[4,5]$.

Преимущество лазерно-искровой эмиссионной спектроскопии (ЛИЭС) заключается в возможности одновременного многоэлементного химического анализа вещества в любом агрегатном состоянии с чувствительностью определения примесей на уровне единиц ppm. Авторы работы [6] продемонстрировали, что метод ЛИЭС с высокой вероятностью позволил идентифицировать в случае природных алмазов их место добычи, а в случае синтетических - лабораторию роста. При этом применялся мультивариативный анализ молекулярных полос излучения $\mathrm{C}_{2}$ и $\mathrm{CN}$ в спектрах лазерной плазмы.

Ранее детально исследовалась лазерно-индуцированная графитизация CVD-алмазов (CVD - chemical vapor deposition) [7,8]. Это явление использовалось при исследовании НРНТ-алмазов методом ЛИЭС [9]. Было обнаружено существенное увеличение интенсивности излучения полосы CN вследствие лазерно-индуцированной графитизации поверхности азотсодержащих алма- зов, и это позволило идентифицировать образцы с малой концентрацией азота (тип ІІа). При этом одновременно наблюдавшийся резкий рост интенсивности полосы $\mathrm{C}_{2}$ однозначно продемонстрировал применимость метода ЛИЭС для выявления структурных связей атомов в исходном образце на примере наблюдавшегося увеличения числа двойных связей атомов углерода $\mathrm{C}=\mathrm{C}$.

$\mathrm{B}$ настоящей работе впервые приведены результаты исследований методом ЛИЭС примесного состава многосекторных азот- и борсодержащих синтетических НРНТ-алмазов. Проведен сравнительный анализ интенсивностей характерных атомарных и молекулярных полос в спектре излучения плазмы исследуемых образцов в условиях лазерно-индуцированной модификации поверхности.

Исследовались крупные многосекторные пластины синтетических алмазов, легированных бором и азотом, размером приблизительно $5 \times 5 \times 0.5 \mathrm{~mm}^{3}$, выращенных компанией „Нью Даймонд Технолоджи“ методом НРНТ (рис. 1). Максимальная концентрация легирующего элемента соответствовала секторам с кристаллографической ориентацией (111) и находилась на уровне $0.5 \mathrm{ppm}$ при легировании образцов бором (тип IIb [10]) и $10,100 \mathrm{ppm}$ при легировании азотом (типы ІІа и Ib соответственно). Это может быть объяснено наличием большей разупорядоченности углеродных связей в секторах (111), чем в секторах (100). В схеме измерений методом ЛИЭС абляция поверхности образцов осуществлялась сфокусированным импульсным излучением $\mathrm{Nd}^{3+}$ : YAG-лазера на длине волны $1064 \mathrm{~nm}$ с плотностью энергии около $1 \mathrm{~kJ} / \mathrm{cm}^{2}$ [9]. Запуск ла- 


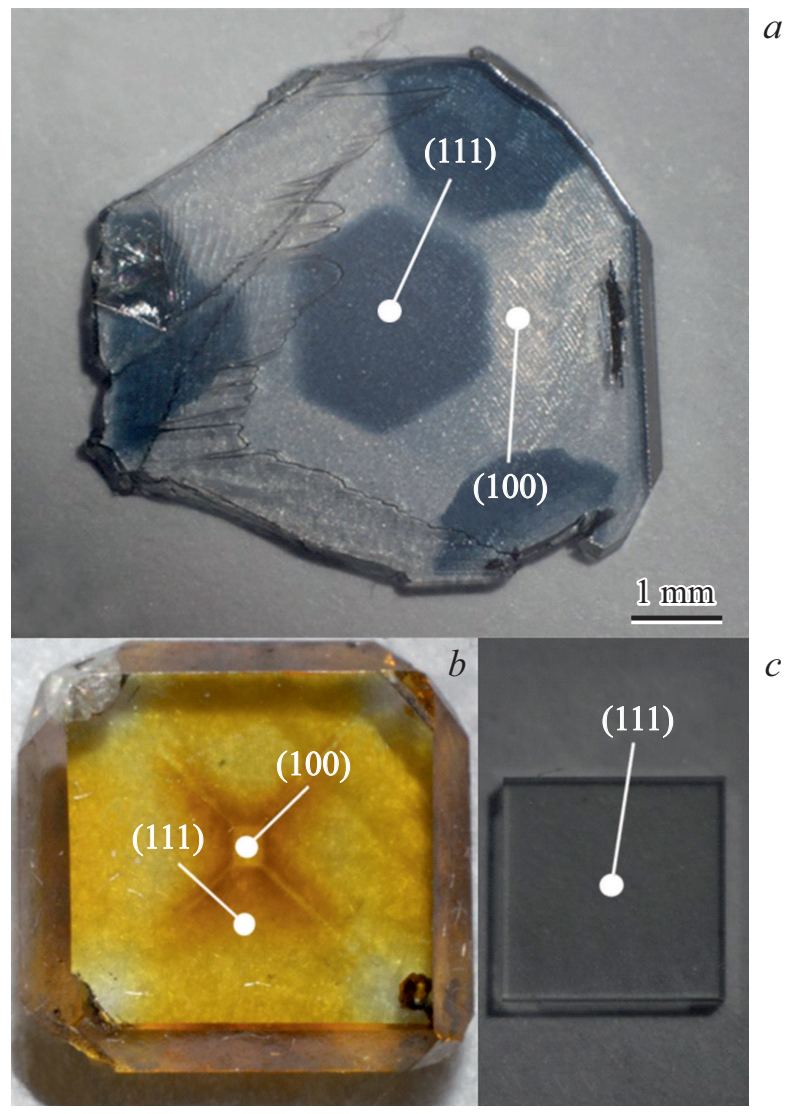

Рис. 1. Внешний вид многосекторальных пластин НРНТ-алмазов. $a-$ пластина, легированная бором $(0.5 \mathrm{ppm})$; $b$ и $c$ - пластины, легированные азотом (100 и $10 \mathrm{ppm}$ соответственно).

зера, синхронизация его работы со спектрометром и обработка спектров плазмы (нормализация, корректировка базовой линии и т.д.) осуществлялись с помощью собственного программного обеспечения [11], а спектры плазмы регистрировались спектрометром с волоконным выходом AvaSpec-ULS2048L (Avantes). Для предотвращения химического взаимодействия лазерного факела с окружающим воздухом образцы обдувались низкоскоростной струей аргона [12].

В процессе последовательной, импульс за импульсом, лазерной модификации поверхности образцов наблюдался рост интенсивности излучения молекулярной полосы $\mathrm{C}_{2}$ (спектральный диапазон 495-517 nm [9]), что являлось следствием увеличения числа двойных связей $\mathrm{C}=\mathrm{C}$ (рис. 2). Такие связи соответствуют $s p^{2}$-гибридизации атомов углерода, и их наличие подтверждается появлением $G$-полосы $\left(1600 \mathrm{~cm}^{-1}\right)$ в спектрах комбинационного рассеяния, что связано с графитизацией поверхности алмаза в зоне абляции [9].

Интенсивность полосы $\mathrm{C}_{2}$ зависела от вида и концентрации легирующего элемента, а также от кристаллографической ориентации сектора алмазной пластины. Максимальный рост наблюдался для сектора (111) образца с высокой концентрацией азота (100 ppm, насыщенный желтый цвет). В этом случае, а также для сектора (100) наблюдался стационарный режим абляции поверхности образца, что проявлялось в отсутствии изменения интенсивности полосы $\mathrm{C}_{2}$ после десятого импульса лазерного излучения (зависимости 1 и 2 на рис. 2). Для низколегированного азотом алмаза $(10 \mathrm{ppm})$, а также для борсодержащих образцов стационарный режим абляции не наблюдался (рис. 2, вставка), причем для алмазов, легированных бором, различие в интенсивностях полосы $\mathrm{C}_{2}$ для секторов (111) и (100) оказалось менее существенным.

Помимо азота и бора характерными примесями, влияющими на электропроводность, теплопроводность и оптические свойства синтетических НРНТ-алмазов, являются примеси водорода и кислорода [13-15]. На рис. 3 представлены зависимости интенсивностей атомарных полос излучения водорода $\left(\mathrm{H}_{\alpha}, \lambda_{\max }=656.28 \mathrm{~nm}\right)$ и кислорода $\left(\lambda_{\max }=777.2 \mathrm{~nm}\right)$ от номера импульса лазерного излучения, т.е. в процессе последовательной лазерноиндуцированной модификации исследуемых образцов. Очевидно, что вид приведенных зависимостей является индикатором как секторной структуры образца, так и вида легирующего элемента (азот, бор). Вхождение водорода в структуру алмаза (рис. $3, a$ ) резко увеличивается с ростом уровня легирования алмаза как азотом, так и бором и существенно зависит от кристаллографической ориентации сектора образца (максимально для ориентации (111)). Однако в случае легирования бором влияние кристаллографической ориентации на вхождение водорода в структуру менее значительно. Не вполне ясны причины резкого падения интенсивности полосы $\mathrm{H}_{\alpha}$ на начальной стадии графитизации (пер-

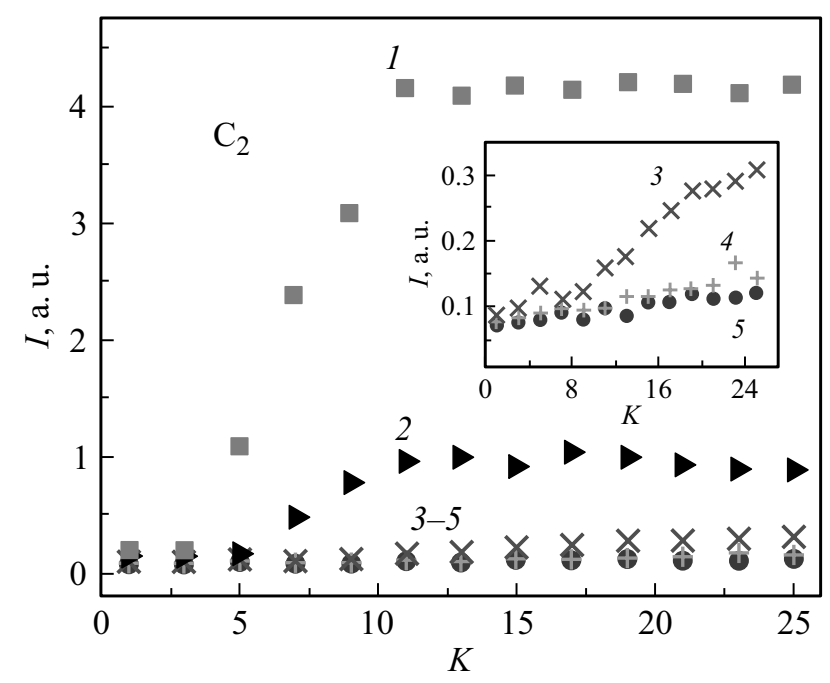

Рис. 2. Зависимости интенсивности $(I)$ полосы $\mathrm{C}_{2}$ от номера лазерного импульса $(K) .1,2-$ сектора $(111)$ и $(100)$ соответственно алмаза с концентрацией азота 100 ppm; 3 - сектор (111) алмаза с концентрацией азота $10 \mathrm{ppm} ; 4,5$ - сектора (100) и (111) соответственно алмаза с концентрацией бора $0.5 \mathrm{ppm}$. 

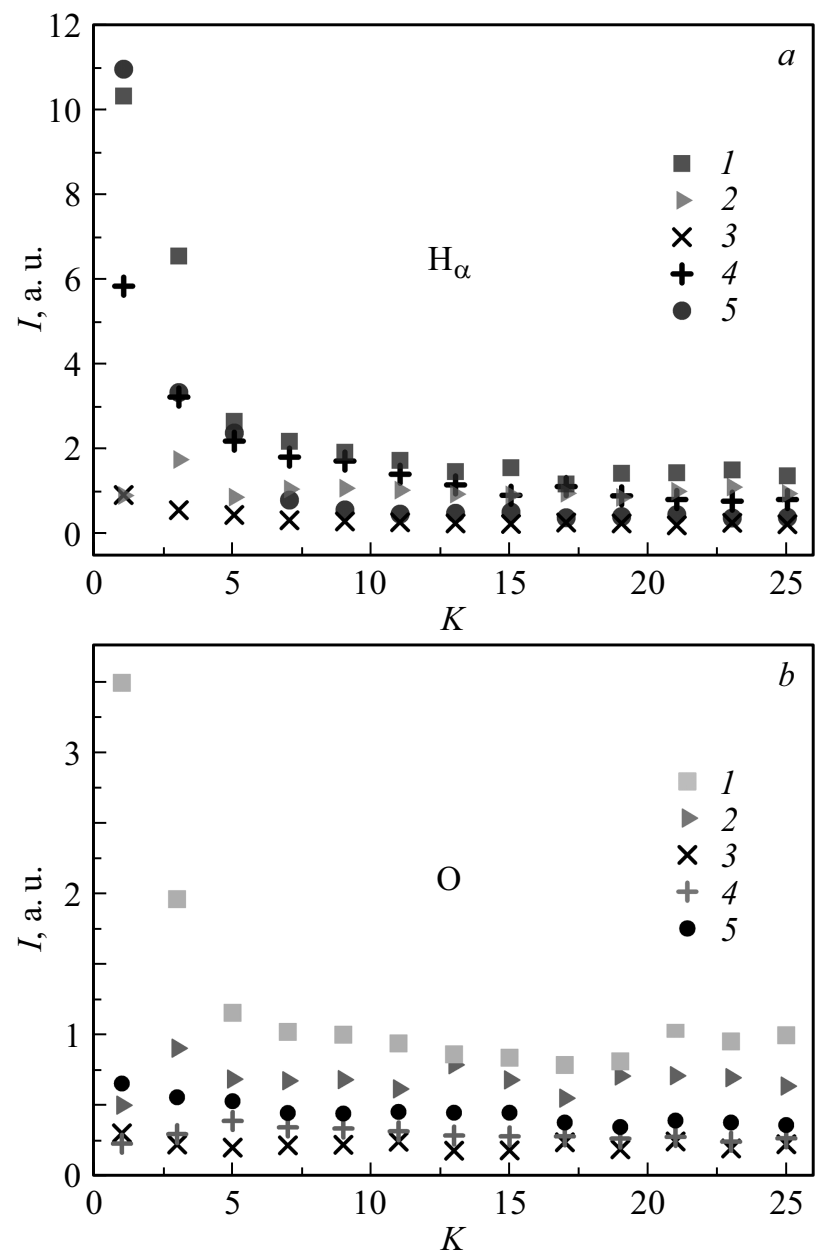

Рис. 3. Зависимости интенсивностей $(I)$ полос $H_{\alpha}(a)$ и $\mathrm{O}(b)$ от номера лазерного импульса $(K)$. Обозначения те же, что на рис. 2.

вые пять лазерных импульсов). Возможно, это падение связано с наличием в структуре сектора (111) достаточно большого количества слабосвязанного водорода, вхождение которого может быть обусловлено большей разупорядоченностью углеродных связей в этом секторе. Это подтверждается ранее проведенным исследованием борсодержащих алмазов методом инфракрасной спектроскопии. Было показано, что вхождение бора максимально для кристаллографической ориентации (111) и минимально для (100) [3]. Для примеси кислорода наблюдаются схожие закономерности (рис. $3, b$ ), однако легирование алмазов бором приводит к значительно меньшему вхождению примеси кислорода в кристаллическую структуру алмаза.

Таким образом, сравнительный анализ интенсивностей характерных для алмаза молекулярных и атомарных полос излучения в процессе лазерно-индуцированной модификации синтетических НРНТ-алмазов может быть полезным при отборе кристаллов с соответствующими электронными и оптическими свойствами для применения в фотонике и электронике.

\section{Благодарности}

Авторы выражают благодарность К.В. Павлову за участие в проведении экспериментов.

\section{Конфликт интересов}

Авторы заявляют, что у них нет конфликта интересов.

\section{Список литературы}

[1] D'Haenens-Johansson U., Katrusha A., Moe K.S., Johnson P., Wang W. // Gems Gemol. 2015. V. 3. P. 260-279.

[2] Tallaire A., Mille V., Brinza O., Tran Thi T.N., Brom J.M., Loguinov Y., Katrusha A., Koliadin A., Achard J. // Diamond Relat. Mater. 2017. V. 77. P. 146-152. https://doi.org/10.1016/j.diamond.2017.07.002

[3] Klepikov I.V., Koliadin A.V., Vasilev E.A. // IOP Conf. Ser.: Mater. Sci. Eng. 2017. V. 286. P. 012035. https://doi.org/10.1088/1757-899X/286/1/012035

[4] Briddon P.R., Jones R. // Physica B. 1993. V. 18. P. 179-189. https://doi.org/10.1016/0921-4526(93)90235-X

[5] Екимов Е.А., Кондрин М.В. // УФН. 2017. Т. 187. № 6. C. 577-598. https://doi.org/10.3367/UFNr.2016.11.037959

[6] McManus C.E., Dowe J., McMillan N.J. // Microsc. Microanal. 2017. V. 23. P. 2282-2283. https://doi.org/10.1017/S1431927617012077

[7] Конов В.И. Углеродная фотоника. М.: Наука, 2017. 327 с.

[8] Konov V.I. // Laser Photon. Rev. 2012. V. 6. P. 739-766. https://doi.org/10.1002/lpor.201100030

[9] Лебедев В.Ф., Павлов К.В., Колядин А.В. // Квантовая электроника. 2018. Т. 48. № 12. С. 1171-1173.

[10] Fridrichová J., Bacik P., Škoda R., Antal P. // Acta Geol. Slovaca. 2015. V. 7. P. 11-18.

[11] Lebedev V.F., Kozlyakov M.S., Stepanov D.N. // Spectr. Acta B. 2017. V. 137. P. 23-27.

[12] Lebedev V.F., Rabchinskii M.K., Kozlyakov M.S., Stepanov D.N., Shvidchenko A.V., Nikonorov N.V., Vul' A.Y. // J. Anal. Atom Spectrom. 2018. V. 33. P. 240-250.

[13] Albin S., Watkins L. // Appl. Phys. Lett. 1990. V. 56. P. 1454 1456. https://doi.org/10.1063/1.102496

[14] Hи X.J., Ye J.S., Liu H.J., Hu H., Chen X.H. // Diamond Relat. Mater. 2011. V. 20. P. 246-249. https://doi.org/10.1016/j.diamond.2010.12.014

[15] Baba K., Aikawa Y., Shohata N. // J. Appl. Phys. 1991. V. 69. P. 7313-7315. https://doi.org/10.1063/1.347580 